\title{
Catalytic Polymerization of Ethylene in Aqueous Emulsion with a Simple In Situ Catalyst
}

\author{
F. M. Bauers, M. M. Chowdhry, S. Mecking*
}

\section{Supporting Information}

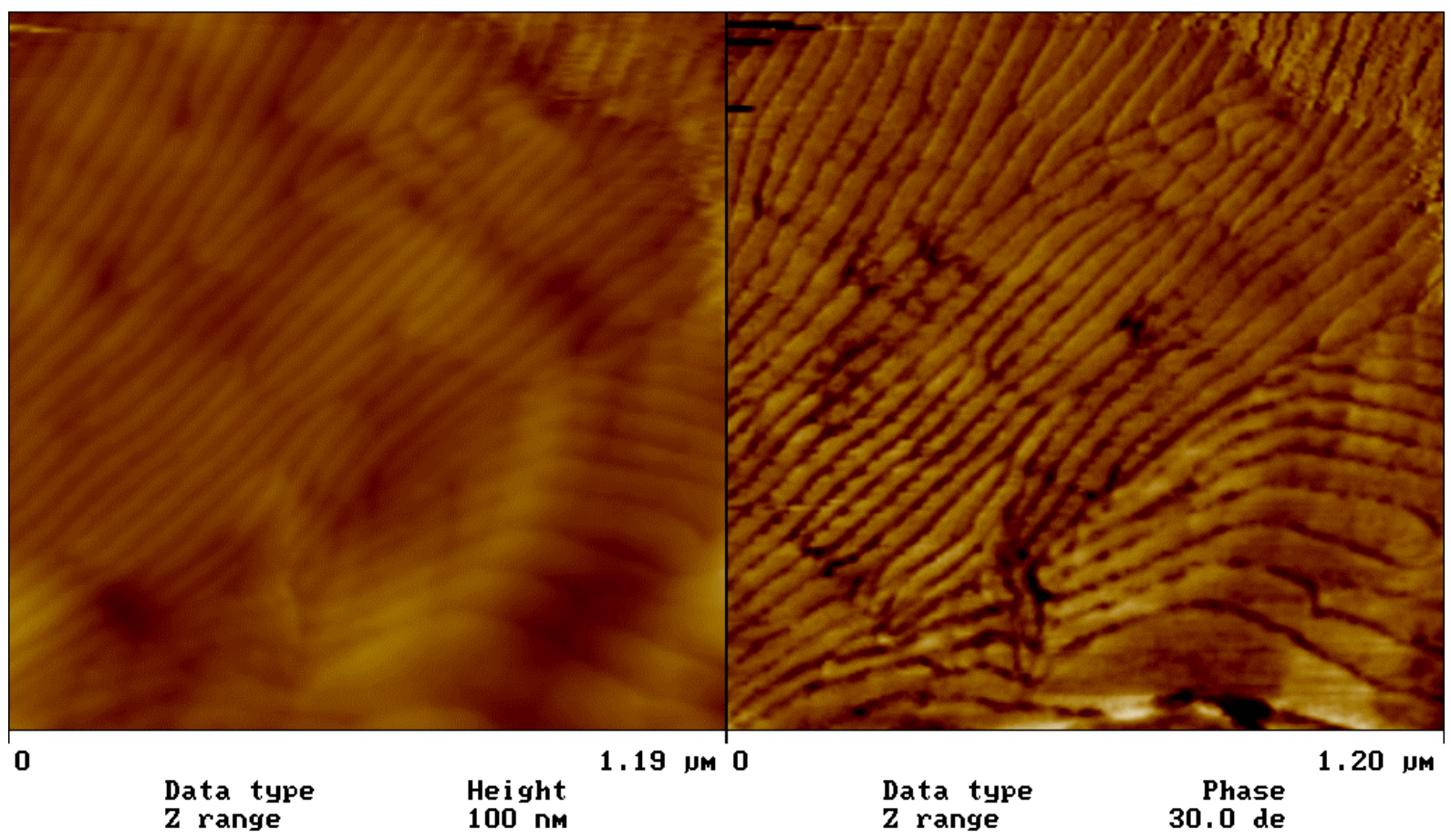

Figure S1. AFM image of a HDPE film (left: height mode, right: phase mode). Note that the polyethylene lamellae are slanted from the perpendicular. 
a)

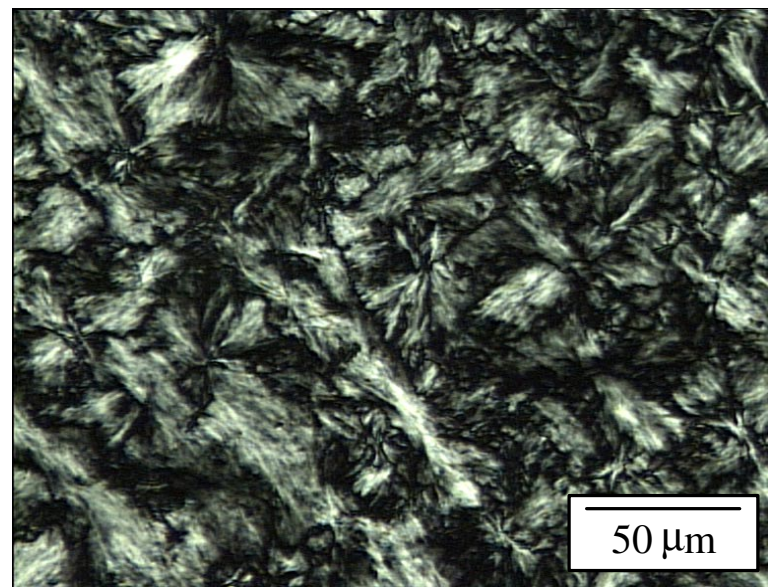

b)

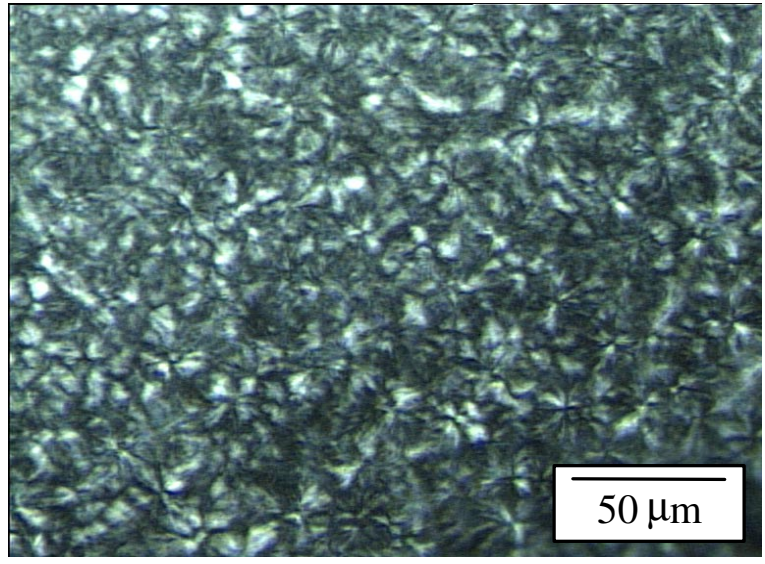

Figure S2. Polarized light microscopy of a film formed from a HDPE dispersion from catalytic polymerization (a) and from a commercial LDPE latex (b). 